\title{
СРАВНЕНИЕ ДАННЫХ, ПОЛУЧЕННЫХ МЕТОДОМ АКУСТИЧЕСКОЙ ИДЕНТИФИКАЦИИ ЧЕРНОМОРСКИХ АФАЛИН (TURSIOPS TRUNCATUS PONTICUS BARABASCH, 1940)
} Логоминова И.В. ${ }^{1}$, Агафонов А.В. ${ }^{2}$, Шатравин А.В. ${ }^{2}$

${ }^{1}$ ФГБУН «Карадагская научная станщия им. Т.И. Вяземского - природный заповедник РАН», 2.Феодосия, пгт. Курортное, Российская Федерация, e-mail: logominova@ rambler.ru

${ }^{2}$ ФГБУН Институт океанологии им. П.П. Ширшова РАН,

2. Москва, Российская Федерачия, е-mail: agafonov.57@mail.ru, ashatravin@ocean.ru

Работа посвящена исследованию двух локальных популяций черноморских афалин. Наблюдения и акустические записи в акватории г. Судак - п. Новый Свет (Крым) осуществлялись круглогодично в течение 2014-2016 гг.; в районе г. Геленджика (Краснодарский край) проводилась регистрация подводной акустической активности дельфинов июне и сентябре 2013 и 2014 гг. В ходе исследований, наряду с визуальной идентификацией особей, впервые в нашей стране применялся метод «акустической идентификации» по составляемому каталогу «свистов-автографов». «Автографы» афалин представляют собой тональные сигналы (свисты) с уникальной для каждого дельфина формой частотного контура и доминирующие в индивидуальном акустическом репертуаре. В таком аспекте «автограф» можно рассматривать как своеобразный «акустический маркер» данной особи. На основании акустических данных была описана структура групп, составляющих исследуемые популяции, представлена сезонная картина посещения акватории различными группами, выделены «транзитные» и «резидентные» группировки.

Ключевые слова: черноморская афалина, акустическая сигнализация, тональные сигналы, «свист-автограф», локальная популяция.

\section{Введение}

На протяжении многих десятилетий особое внимание исследователей всего мира, изучающих китообразных, привлекает афалина (Tursiops truncatus Montagu, 1821). В настоящее время именно этот вид считается наиболее изученным, что, отчасти, связано с тем, что эти дельфины широко распространены и ведут, как правило, прибрежный образ жизни. По многочисленным наблюдениям, афалины предпочитают прибрежные акватории, дальних миграций не совершают, достаточно стабильные группы обитают на относительно локальных участках (Белькович, Агафонов,1978; Caldwell, Caldwell, 1965). Согласно зарубежным исследованиям, установлено, что афалины территориальны и имеют особые «сердцевинные» места в пределах индивидуальных участков; разные участки могут пересекаться между собой. Группы могут объединяться в более крупные, но менее устойчивые скопления - стада, которые, в свою очередь составляют обособленное сообщество; при этом полная изоляция между группами отсутствует и происходит обмен членами групп (Scott et al., 1990; Odell, Asper, 1990).

В нашей стране комплексные исследования свободноживущих черноморских афалин (Tursiops truncatus ponticus Barabasch, 1940), проводились в 70-х - 80-х годах 
XX века на побережье Крыма (в районе п-ова Тарханкут) совместно Институтом океанологии им. П.П. Ширшова АН СССР и Московским государственным университетом. Было установлено, что популяция афалин Чёрного моря представлена локальными субпопуляциями, т.е. совокупностями особей, обитающих на данном участке акватории. Структурными составляющими такой локальной субпопуляции являются: группа, стадо, косяк. Стадо представляет собой естественную группировку дельфинов, характеризующуюся использованием определенной акватории, единством жизнедеятельности, и возможно, родством животных между собой. Группа является составной частью стада; самостоятельно группы существуют в течение не очень продолжительных периодов времени и характеризуются бо̀льшим единством деятельности. Косяк рассматривается как временное, неустойчивое объединение нескольких стад (Белькович, Агафонов и др., 1978).

Таким образом, основной структурной единицей популяции афалин является группа животных. Группы, соответственно, объединяются в стада, а совокупность стад образует локальную популяцию афалин. Стадо афалин характеризуется относительной стабильностью и долговременным самостоятельным существованием. Групповая структура стада дельфинов - лабильный и тонко настроенный механизм для обеспечения оптимальных условий пространственно-временного использования акватории, а также адекватных способов охоты при изменяющихся условиях среды. Тем не менее, можно предположить наличие постоянной «центральной» группировки одной или нескольких групп, которая составляет основу стада, к которой могут присоединяться группы дельфинов. Кроме того, от стада могут отделяться отдельные группы, начинающие самостоятельное существование и дающие начало формированию новых стад (Белькович, Агафонов, 1978).

Подводная акустическая сигнализация афалин также является важным аспектом в изучении данного вида дельфинов. В настоящее время общепринято, что звуковые сигналы афалин можно разделить на три категории: 1) серии широкополосных импульсов (щелчки); 2) тональные сигналы (свисты) с различной формой контура частоты основного тона; 3) импульсно-тональные сигналы, представляющие собой серии импульсов с высокой частотой следования (150-700 имп/с), при этом считается, что первая категория сигналов используется дельфинами для эхолокации, две остальные - для коммуникации (Lilly, Miller, 1961; Caldwell, 1990). Одним из ключевых моментов в изучении звуковых сигналов, свойственных данному виду, стало открытие Д. и М. Колдуэллами в середине 60-х годов XX века «свистов-автографов» («signature whistles») (Caldwell, Caldwell, 1965). «Автограф» определяется, как свистовой сигнал с уникальной для каждого животного формой частотного контура, являющийся доминирующим в репертуаре данной особи. В таком аспекте его можно рассматривать как своеобразный «акустический маркер» данной особи. Предполагается, что данный тип сигнала используется афалинами для идентификации особей-продуцентов и их местоположения в море, для поддержания единства группы (Janik, 2013).

Работы последних лет показывают, что подавляющее большинство тональных сигналов афалин представляет собой систему «персонифицированных» (т.е. продуцируемых только конкретными особями) сигналов. «Автограф» является «ядром» этой системы, и в таком аспекте его можно рассматривать как своеобразный «акустический маркер» особи (Агафонов, Панова, 2012, 2017). Благодаря характерной форме контуров (т.е. их персональной специфичности), «автографы» пригодны для использования в качестве идентификационных, а также для определения взаимного местоположения особей при разделении стада (группы). Для автографов характерно их продуцирование сериями; на протяжении серии могут наблюдаться небольшие вариации частотного контура. 
Таким образом, составляя каталог регистрируемых «автографов», возможно (в сочетании с визуальными наблюдениями) с достаточно высокой точностью проводить учет численности и миграций афалин в естественной среде, а также описывать динамику социальной структуры их популяций.

\section{Материалы и методы}

Комплексные исследования локальной популяции афалин, включающие запись их подводной акустической сигнализации, были начаты в мае 2014 года на юго-восточном побережье Крыма, в акватории Новосветских бухт (пгт. Новый Свет - г. Судак) (рис. 1). Работы проводятся круглогодично и продолжаются в настоящее время. Кроме того, были обработаны акустические записи, собранные Институтом океанологии РАН (Южное отделение) в районе г. Геленджика (Краснодарский край) в 2013 и 2014 гг. (рис. 1). Регистрация подводной акустической активности афалин осуществлялась в двух наблюдательных пунктах: на выходе из Геленджикской бухты и в Рыбацкой бухте (рис. 2).

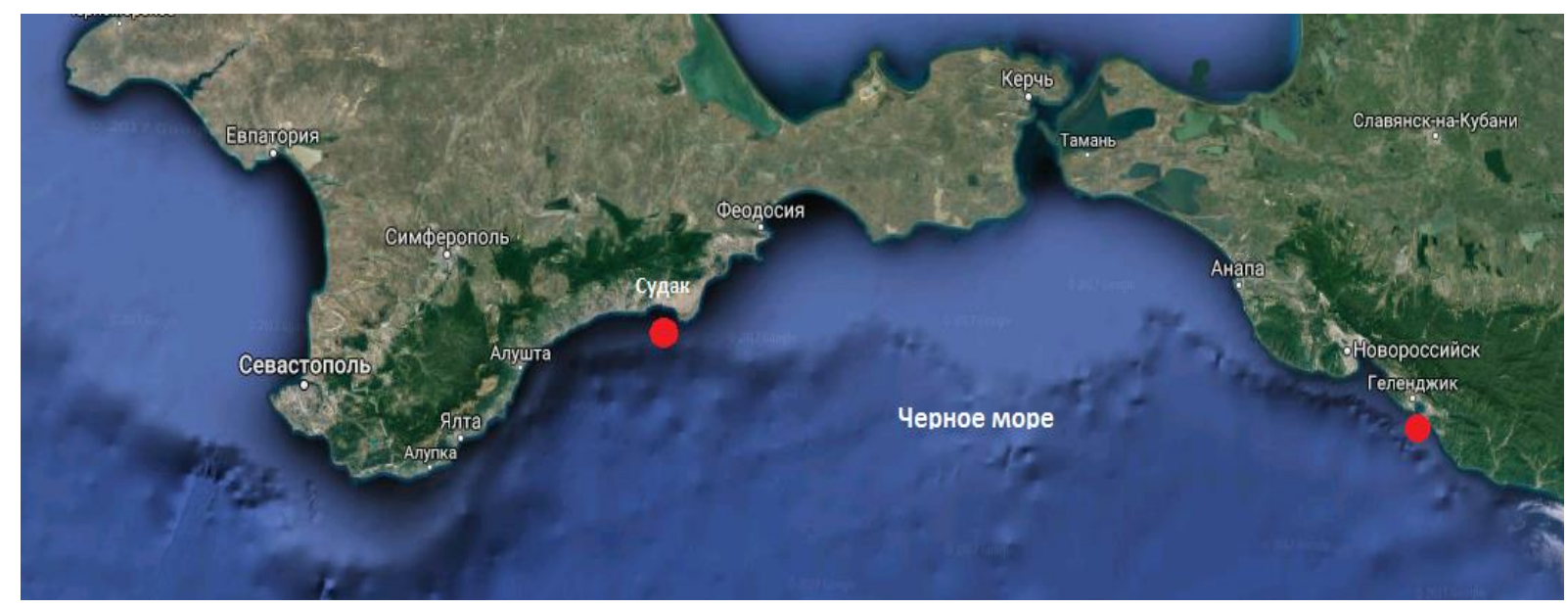

Рис. 1. Районы сбора акустического материала, акватория г. Судак - пгт. Новый Свет, акватория г. Геленджик.

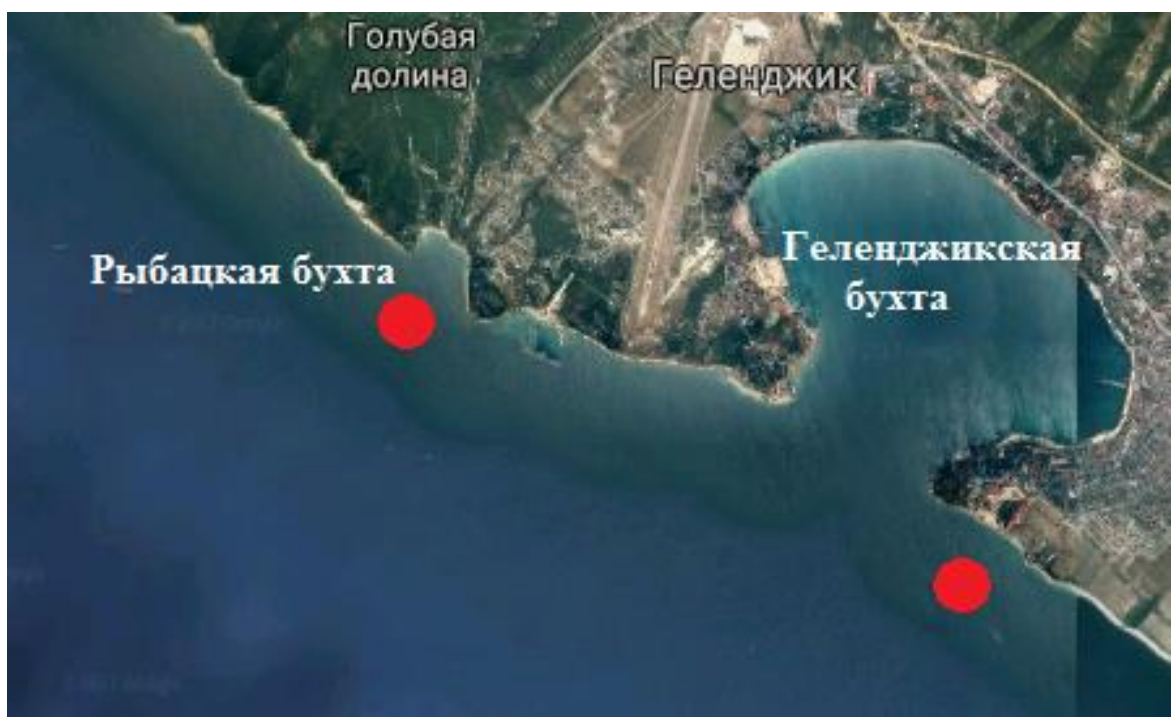

Рис. 2. Стационарные пункты в акватории г. Геленджик по сбору акустических данных. 
Для сбора акустических данных использовался стандартный гидроакустический тракт, состоящий из гидрофона, предварительного усилителя, кабеля и наземного усилителя-коммутатора; акустические записи проводились в монофоническом (одноканальном) режиме. В качестве регистрирующего устройства применялся цифровой рекордер ZOOM H1, формат записи PCM (WAV), 16 бит, частота дискретизации 44,2 кГц (диапазон записи 0,1-22,1 кГц). Акустические записи в акватории г. Судак - пгт. Новый Свет велись как стационарно с берега, так и с моря, с использованием катера и прогулочных педальных катамаранов. В журнал наблюдений по стандартной схеме заносились данные о перемещении дельфинов по акватории, наблюдаемом численном и возрастном составе групп, характере поведенческой активности.

В районе г. Геленджик акустические записи осуществлялись при помощи стационарных подводных гидроакустических комплексов.

Обработка акустических сигналов проводилась при помощи программы Adobe Audition 1.5 при следующих установочных параметрах: размер блока быстрого преобразования Фурье 256-1024 точек, весовая функция Хемминга. Программа позволяет визуализировать обрабатываемые сигналы в спектральном или волновом виде и производить точные замеры их частотно-временных параметров. При сравнении зарегистрированных свистов измерялись следующие параметры: длительность сигнала и его отдельных элементов, а также начальная, конечная, минимальная и максимальная частота основного тона (рис. 3).

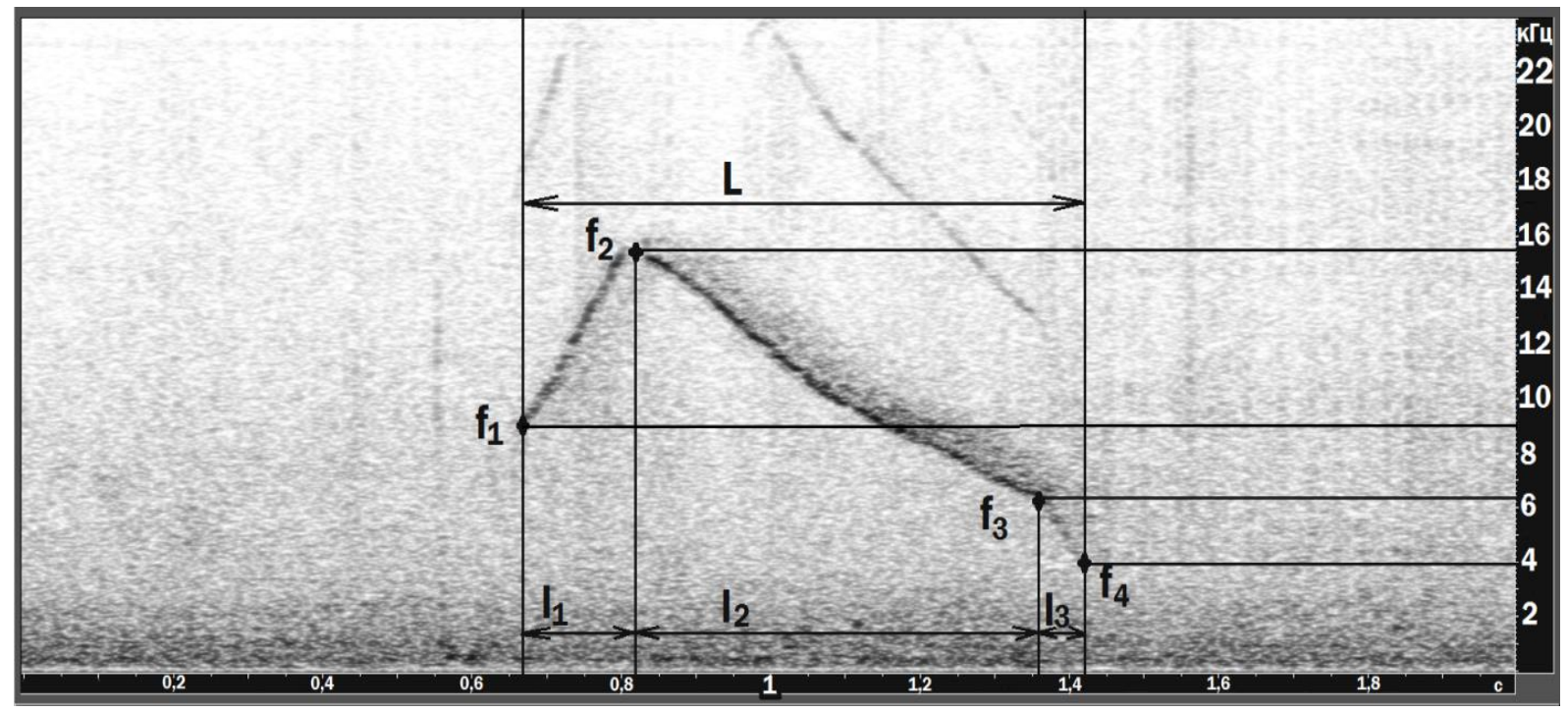

Рис. 3. Структура типичного «свиста-автографа» (по: Агафонов и др., 2016): L общая длительность сигнала, $l 1-l 3$ - длительность отдельных элементов, $f 1-f 4$ часто̀ты «ключевых точек» сигнала.

\section{Результаты и обсуждение}

За период с мая 2014 года по декабрь (включительно) 2016 года, в акватории г. Судак - пгт. Новый Свет, было проведено 302 дня наблюдений. Общий объем акустических записей составляет 496 часов; всего зарегистрировано 57333 тональных (свистовых) сигналов, качество которых приемлемо для дальнейшей обработки. При анализе записей выделено 305 доминирующих типов свистов. Сходные сигналы, как правило, продуцировались дельфинами в виде последовательностей; общее количество свистов, отнесенных к одному типу (вариаций), могло составлять от нескольких 
десятков до нескольких сотен. По результатам систематизации и анализа зарегистрированных сигналов составлен каталог «свистов-автографов», каждому из которых присвоен порядковый номер (рис. 4).

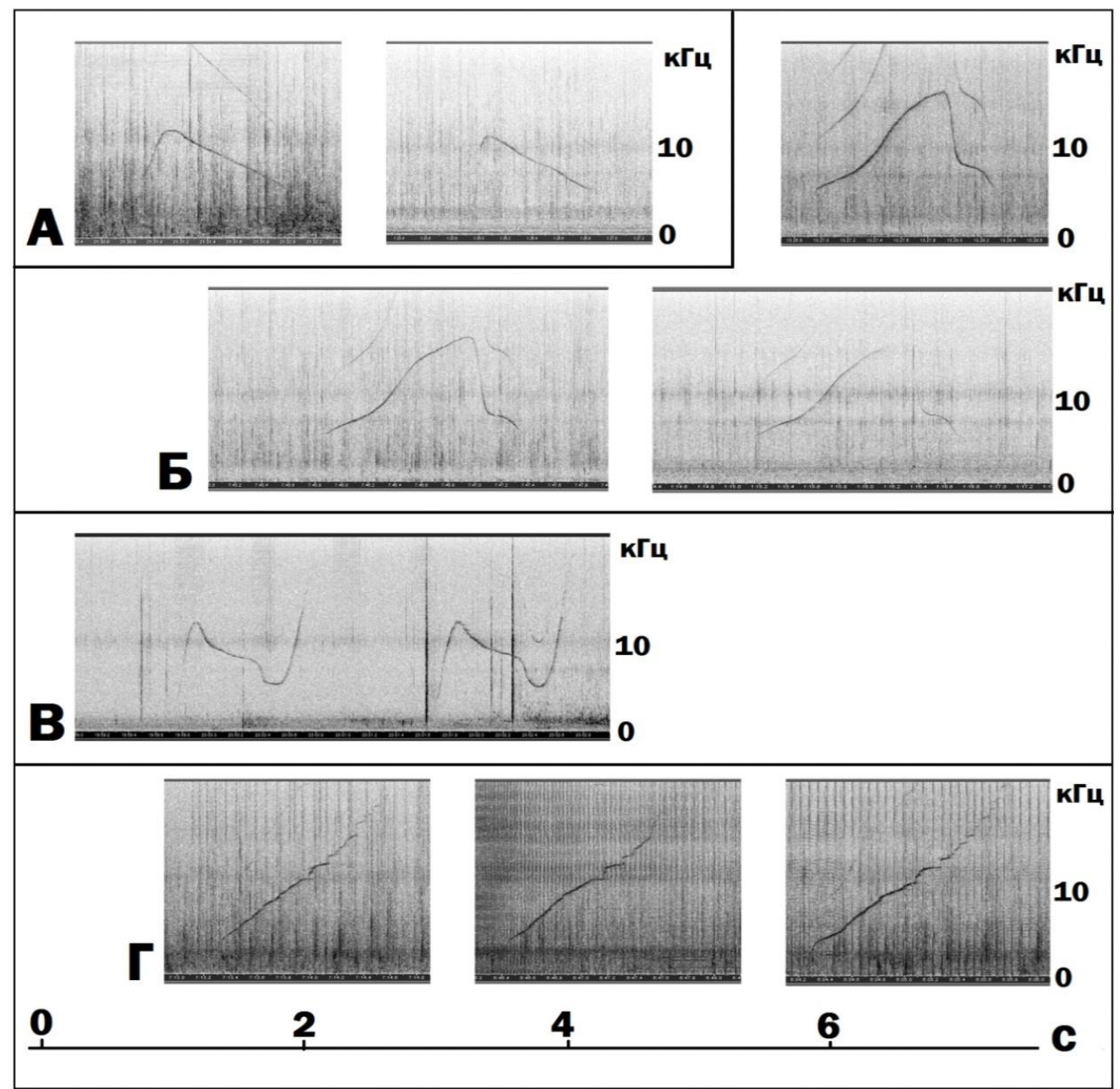

Рис. 4. Примеры спектрограмм некоторых из «свистов-автографов», зарегистрированных в акватории г. Судак - пгт. Новый Свет

Характер распределения частоты встречаемости зарегистрированных типов «свистов-автографов» отображен на рис. 5: на графике по горизонтали указано число дней наблюдений, в течение которых наблюдались данные типы «свистов-автографов», по вертикали отображено общее количество типов «свистов-автографов», наблюдавшихся в течение данного числа дней. Можно заметить, что перелом кривой распределения на графике наблюдается между значениями 5 и 6 дней. Соответственно, выделяются две совокупности «свистов-автографов»: 247 типов, регистрировавшиеся в течение 1-5 дней и 58 типов в течение 6-22 дней.

Таким образом, на основании количественной встречаемости соответствующих «свистов-автографов» в акватории были выявлены две характерные группировки дельфинов. Первая группировка, представленная 247 типами «свистов-автографов», состоит из особей, которые посещают акваторию нерегулярно, т.е. являются «транзитными». Вторая же группировка (58 типов «свистов-автографов») - это афалины, которые регулярно заходят в исследуемую акваторию, независимо от сезона, и являются «резидентными» особями. 


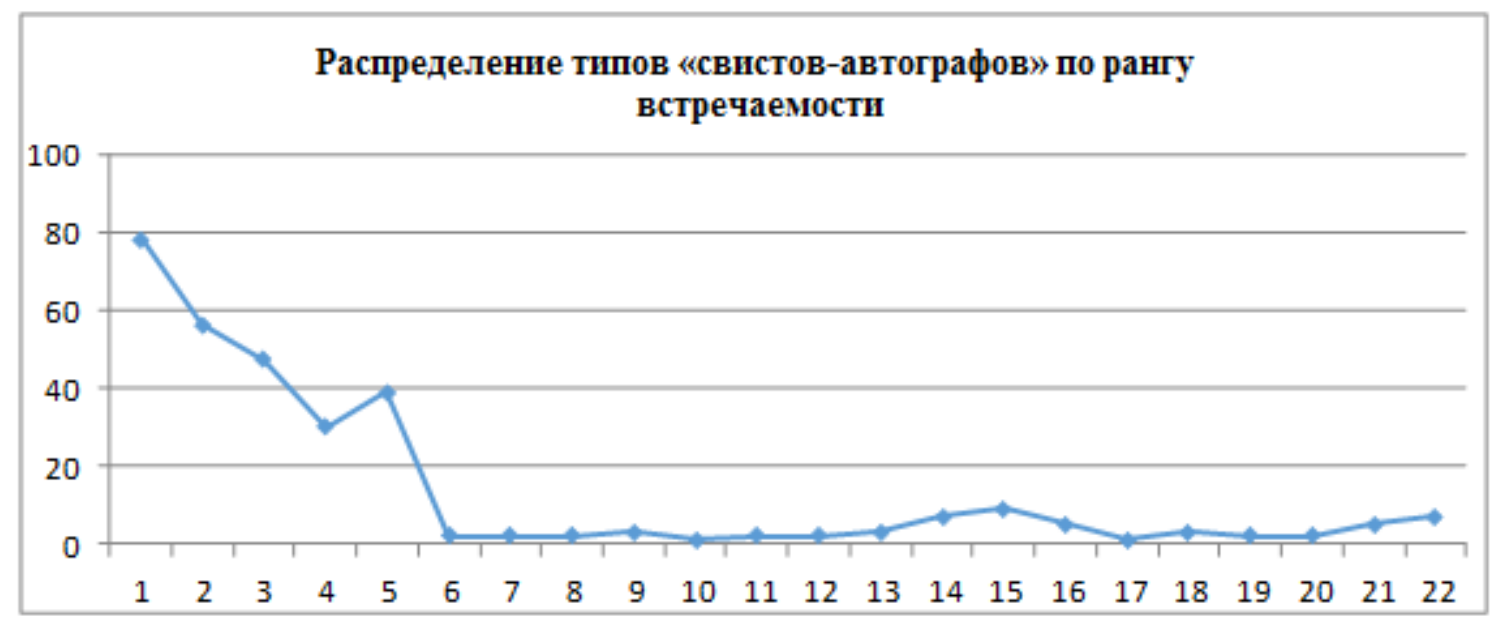

Рис. 5. Динамика распределения типов «свистов-автографов»

Акустические записи, сделанные в акватории г. Геленджик, выполнены в течение июня и сентября 2013 и 2014 гг. Общий объем акустических записей составляет более 1000 часов; всего зарегистрировано 13890 тональных (свистовых) сигналов, качество которых приемлемо для дальнейшей обработки. В ходе предварительной обработки записей выделено 34 доминирующих типов свистов (рис. 6).

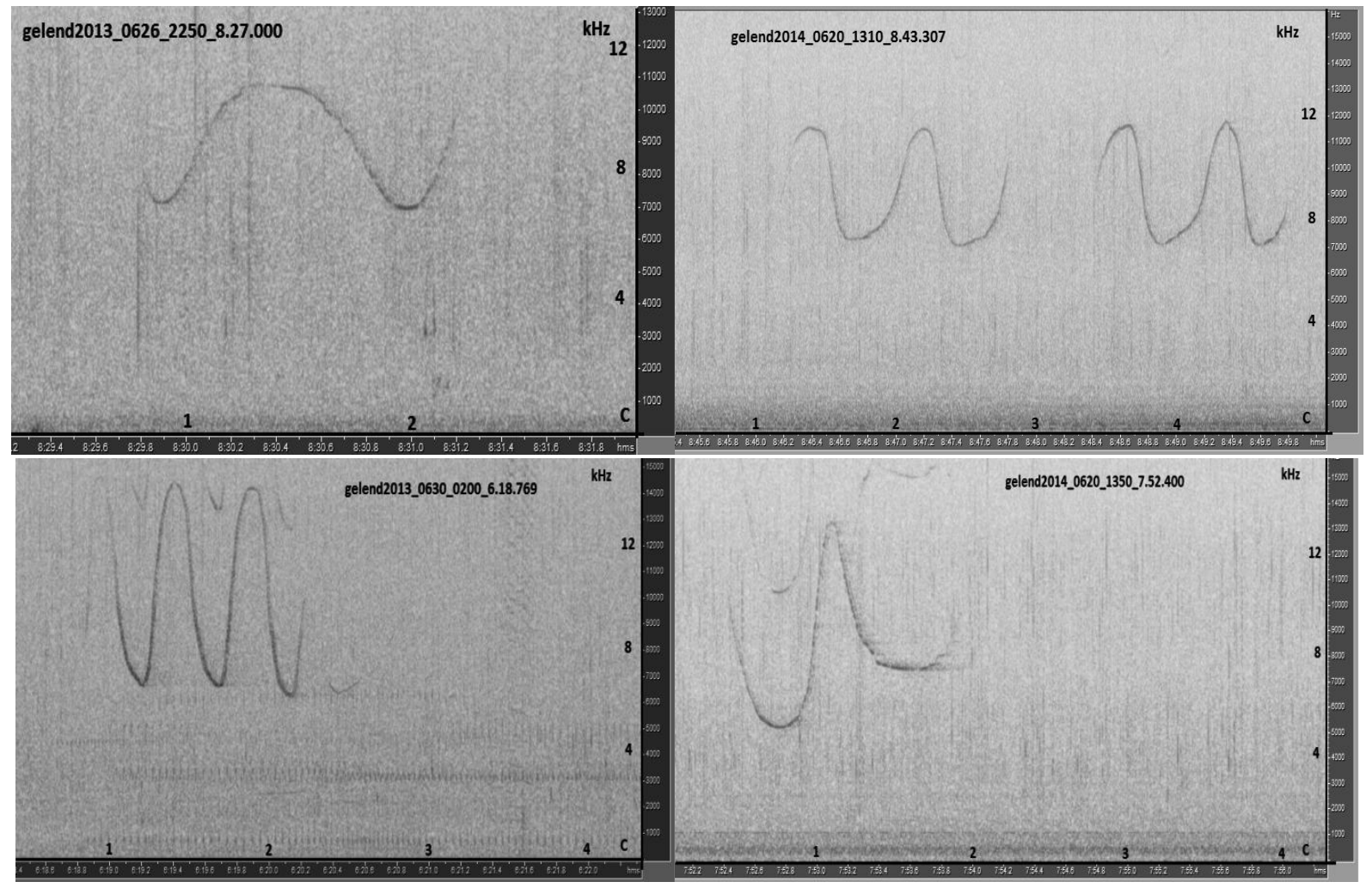

Рис. 6. Примеры спектрограмм некоторых «свистов-автографов» афалин, зарегистрированные в акватории г. Геленджик.

Проведя анализ количественной встречаемости «свистов-автографов», также можно говорить о существовании в исследуемом районе двух группировках афалин. К первой группировке относится 16 типов, регулярно регистрируемых «свистов- 
автографов»; они принадлежат группе афалин, которая относительно часто посещала исследуемую акваторию, и является, таким образом, «резидентной». 18 типов «свистовавтографов» отмечались нерегулярно (некоторые типы - однократно); соответственно, данная группа является «транзитной».

Распределение частоты встречаемости зарегистрированных типов «свистовавтографов» отображен на рис. 7. На графике по горизонтали указано число дней наблюдений, в течение которых наблюдались данные типы «свистов-автографов», по вертикали отображено общее количество типов «свистов-автографов», наблюдавшихся в течение данного числа дней. Исходя из приведенного графика, наблюдается перелом кривой распределения, который проходит между значениями 3 и 4 дня, т.е. общее число типов «свистов-автографов», которые регистрировались в течение 1-3 дня - 18 типов, и на протяжении 4-8 дней - 16 типов «свистов-автографов».

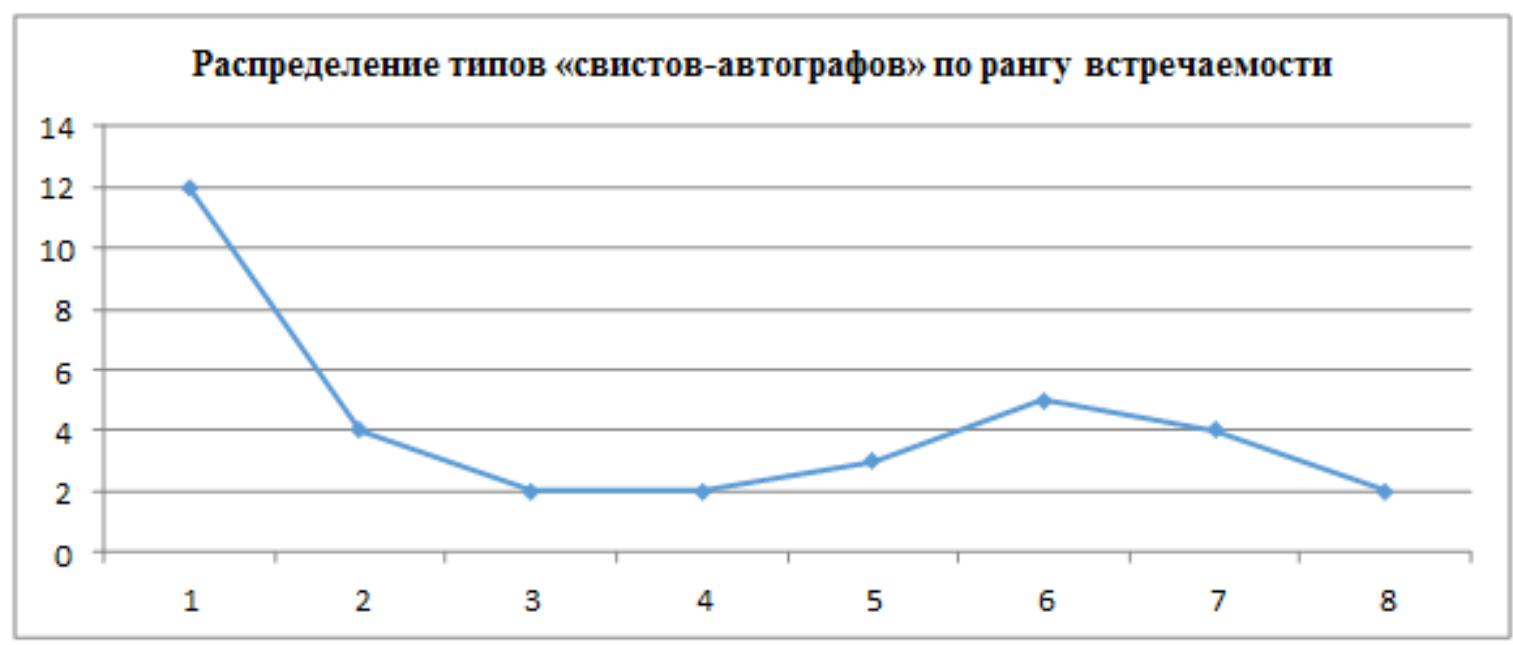

Рис. 7. Динамика распределения типов «свистов-автографов»

Как было сказано ранее, по многочисленным наблюдениям отечественных исследователей, афалины предпочитают прибрежные акватории, не совершают дальних миграций, стабильные группы обитают на относительно локальных участках.

На основании анализа собранного нами акустического материала складывается представление о достаточно сложной социально-временной структуре исследуемых локальных популяций афалин. Так, результаты исследований, проведенных в акватории г. Судак - пгт. Новый Свет, показали, что существующая в данном месте популяция состоит из отдельных групп, численностью 4-8-12-14 особей, которые, в свою очередь, могут создавать более крупные временные объединения.

Следует отметить, что группы афалин, которые посещают Новосветскую акваторию, динамичны, четко выраженной границы между группами не наблюдается. Возможен переход пар и отдельных особей из группы в группу, а также характерно объединение нескольких групп в стада, численностью 20-50 особей. Таким образом, полученные нами данные, подтверждаются информацией по проведенным ранее исследованиям о формировании групп и численном составе.

При проведении акустико-визуальных наблюдений, количество типов «свистовавтографов» примерно соответствует числу особей, наблюдаемых в периоды выполнения акустических записей. Как отмечалось ранее, вероятнее всего «свистыавтографы» используются афалинами для идентификации особей при разделении и объединении групп, для определения месторасположения продуцентов сигналов в море, для поддержания единства группы, и т.д., то есть - выполняют индивидуально- 
опознавательную и социальную функцию. Наши работы подтверждают подобные представления.

\section{Выводы}

Количество регистрируемых типов «свистов-автографов», на примере данных, полученных в акватории г. Судак - пгт. Новый Свет, примерно соответствовало числу особей, наблюдаемых в периоды проведения акустических записей, что подтверждает основную функциональную роль этих сигналов, как индивидуально-опознавательных.

На основании проведенной оценки общего количества зарегистрированных типов «свистов-автографов» по частоте их встречаемости и сопоставления сезонной динамики появления тех или иных типов «свистов-автографов», выделяются две пространственно-временные группировки их продуцентов. К первой относятся «свисты-автографы» особей, которые посещают акваторию нерегулярно, т.е. являются «транзитными». Вторая группировка включает в себя особей, которые достаточно регулярно заходят в исследуемые акватории, т.е. являются «резидентными». Похожая картина наблюдается и при анализе акустических данных, собранных в районе г. Геленджика.

Проведенные исследования показали, что применение акустических методов идентификации афалин (в сочетании с визуальными методами наблюдений) значительно повышает эффективность и точность учета численности и миграций, а также описания пространственно-временной структуры популяций дельфинов данного вида.

\section{Список литературы}

1. Агафонов A.B., Панова E.M. Индивидуальный репертуар тональных (свистовых) сигналов афалин (Tursiops truncatus), содержащихся в дельфинарии в условиях относительной изоляции // Известия РАН. Серия биологическая. - 2012. - №5. C. $125-135$.

2. Агафонов А.В., Панова Е.М., Логоминова И.В. Типология тональных сигналов афалин (Tursiops truncatus). - М.: POО CMM, 2016. - 143 с.

3. Агафонов A.B., Панова E.M. Тональные сигналы (свисты) афалин (Tursiops truncatus) как система персонифицированных акустических коммуникативных сигналов // Общая биология. - 2017. - Т. 78. - №1. - С. 38-55.

4. Белькович В.М. Поведение и биоакустика дельфинов. - М.: ИОАН СССР, 1978. $199 \mathrm{c}$.

5. Caldwell M.C., Caldwell D.K. Individualized whistle contours in bottlenose dolphins (Tursiops truncatus) // Nature. - 1965. - V. 207. - P. 214-219.

6. Caldwell M.C., Caldwell D.K., Tyack P.L. Review of the signature-whistle hypothesis for the Atlantic bottlenose dolphin (Tursiops truncatus) // The Bottlenose Dolphin. - San Diego: Academic Press, 1990. - P. 199-234.

7. Janik V.M., Sayigh L.S Communication in bottlenose dolphins: 50 years of signature whistle research // J. Comp. Physiol. A. - 2013. - P. 243-251.

8. Lilly J.C., Miller A.M. Vocal exchanges between dolphins // Science. - 1961. - V. 134. № 3493. - P. 78-79.

9. Odell D.K., Asper E.D. Distribution and movements of freeze-branded bottlenose dolphins in the Indian and Banana rivers, Florida // The Bottlenose Dolphin (Leatherwood, Reeves, (Eds). - San Diego, New York, 1990. - P. 354-365. 
10. Scott M.D., Wells R.S., Irvine A.B. A long-term study of bottlenose on the West coast of Florida // The Bottlenose Dolphin (Leatherwood, Reeves (Eds.). - San Diego, New York, 1990. - P. 235-244.

\section{COMPARISON OF INFORMATION OBTAINED BY THE METHOD OF ACOUSTIC IDENTIFICATION OF THE BLACK SEA BOTTLENOSE DOLPHINS (TURSIOPS TRUNCATUS PONTICUS BARABASCH, 1940) \\ Logominova I.V. ${ }^{1}$, Agafonov A.V. ${ }^{2}$, Shatravin A.V. ${ }^{2}$ \\ T.I.Vyazemsky Karadag Scientific Station - Nature Reserve of the RAS, Feodosia, Kurortnoe, Russian Federation, e-mail: logominova@rambler.ru P.P. Shirshov Institute of Oceanology, Moscow, Russian Federation, e-mail:agafonov.57@mail.ru, ashatravin@ocean.ru}

The work is devoted to the study of two local populations of the Black Sea bottlenose dolphins. Observations and acoustic recordings in the water area of the city of Sudak - Novy Svet (Crimea) were implemented all year round during 2014-2016; in the region of Gelendzhik (Krasnodar) underwater acoustic activity of dolphins was registered in June and September 2013 and 2014. In the course of research, along with visual identification of individuals, for the first time in our country the method of "acoustic identification" was used for the compiled catalog of "Signature whistles". "Signature whistles" of bottlenose dolphins are tonal signals (whistles) with a unique form of frequency contour for each dolphin and dominant in individual acoustic repertoire. In this aspect, the "signature whistles" can be regarded as a kind of "acoustic marker" of this individual. On the basis of acoustic data, the structure of the groups composing the populations under study was described, the seasonal pattern of visiting the water area by various groups was presented, and "transit" and "resident" groups were identified.

Key words: Black Sea bottlenose dolphin, acoustic signaling, tonal signals, "signature whistles", local population. 